\section{Open cup for young children} receives accreditation

The Oral Health Foundation has given its seal of approval to Babycup, the first open cup specially designed for infants' and toddlers' small hands. The Foundation's expert panel has accredited the product, which helps aid good oral health in young children by encouraging healthy sipping and natural drinking as well as supporting oral development.

Each product that passes through the charity's panel of experts is awarded an 'Oral Health Foundation Approved' status once their claims have been rigorously checked and effectively verified, including a logo and accreditation document. Prior to their accreditation, Babycup had won multiple awards. The cup holds $50 \mathrm{ml}$ of liquid and has a slim drinking edge designed for young mouths.

The cup is perfect for any infant between $0-2.5$ years as it can be used right from birth, whether you're express feeding, using formula or a combination of the two. It's much better for oral development than a traditional 'sippy cup' because it encourages natural sipping instead of prolonged sucking.

Nigel Carter, Oral Health Foundation $\mathrm{CEO}$ and dentist for over 40 years said: 'We welcome this new partnership with Babycup and are happy to provide them with accreditation for their cup product. This is the first free drinking cup for tiny hands to be approved by the panel.

'Developing proper drinking habits at an early age is vital for oral development. Primary [milk] teeth are crucial to jaw development, speech development and adult teeth placement.'

Founder of Babycup Sara Keel said: 'Receiving the seal of approval from the Oral Health Foundation is a great achievement and recognises the importance of our mini open cups in the eyes of oral healthcare experts'.

There are lots more products approved by the Oral Health Foundation for babies, toddlers and young children. To find out more about Babycup visit www.babycup.co.uk.

\title{
The new paintable colour-and-form ceramic system
}

The GC Initial full range dental ceramic system speeds up laboratory workflow with a new and highly aesthetic, paintable colour-and-form ceramic system.

Laboratories, dentists and patients all have increasing aesthetic expectations and GC has met and exceeded those expectations with Initial IQ ONE SQIN which facilitates the design of highly aesthetic posterior restorations made from lithium disilicate or zirconia, avoiding cumbersome and time-consuming layering techniques. It is also suitable for the anterior region, thanks to an efficient and easy-to-apply approach.

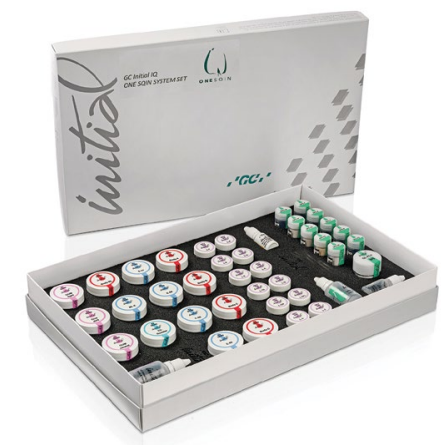

Based on the GC Initial 'IQ philosophy', Initial IQ ONE SQIN consists of different perfectly adapted ceramic materials, assuring efficient and outstanding aesthetic finishing of single monolithic and buccally reduced restorations that compare favourably to the aesthetic result of conventionally layered restorations.

For full monolithics, the new Initial IQ Lustre Pastes ONE feldspar-based 3D paint-on ceramic adds colour depth and lifelike translucency with a genuinely natural glaze. The inherent fluorescence helps to fine-tune and boost the overall fluorescence of every monolithic restoration.

For buccally reduced monolithics, Lustre Pastes ONE can be used as a colour and individualisation layer and to ensure a perfect connection firing before application of the new SQIN ceramics in the micro-layering technique. The SQIN ceramic is easily applied in a thin layer of $0.1-0.6 \mathrm{~mm}$ over the painted and fired Lustre Pastes ONE surface. Thanks to the refined mixture of feldspar-based glasses, a lifelike 3D-effect is created, resulting in colour depth and lifelike translucency. The system's unique application and modelling properties also facilitate individual surface texturing, with self-glazing properties.

The unique Initial IQ ONE SQIN concept ticks all the boxes:

- Create form and fine texture details in the wet stage - no changes after firing

- Self-glazing properties - get a beautiful glazed finish in one single firing

- Optimal fluorescence level - ensures the look of natural teeth under all light conditions

- Maximal aesthetics within a micro-layer

- For all zirconia and lithium disilicate restorations.

For more information on GC Initial IQ ONE SQIN contact GC UK Ltd on 01908 218999, email info.uk@gc.dental or visit europe.gc.dental/products/initialiqonesqin.

\section{Sophisticated air purification}

There are numerous benefits to investing in the JADE Air Purification System from Nuview. This medical grade device combines a contemporary design with sophisticated six-stage filtration and sterilisation technology, making it ideal for use in dental practices.

The JADE system is capable of removing a wide range of indoor air pollutants, helping to minimise discomfort among patients and staff. It can also help to limit absenteeism by reducing the risk of disease transmission via contaminated aerosols, thereby ensuring a tangible return on investment. With integrated smart control features, the JADE

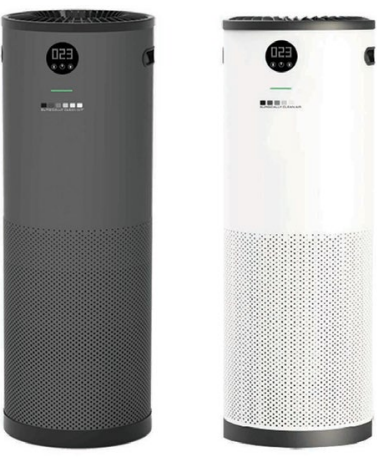

system makes purifying indoor air simple and straightforward. Call Nuview to order now.

For more information call Nuview on 01453 872266, email info@nuview-ltd.com or visit www.nuview.co.uk. 